\title{
Possibilities of Dance Therapy and its Comprehensive Benefits for Children with Autism
}

\author{
Diana Kim¹, Kathryn Marks ${ }^{1 \#}$ and Stacy Gil\# \\ ${ }^{1}$ Tappan Zee High School, Orangeburg, USA \\ \#Advisor
}

\section{$\underline{\text { ABSTRACT }}$}

Dance Therapy (DT) is an effective treatment to promote emotional, social, cognitive and physical integration of the individual. Its benefits are of particular interest in children with Autism Spectrum Disorder (ASD), whose caretakers are burdened with the high cost and rigorous demand of treatment. Furthermore, the effectiveness of the Treatment and Education of Autistic and Related Communications-Handicapped Children (TEACCH) program, the most widely used curriculum for children with ASD have been called into question. This paper proposes a revamping of physical education of students with ASD with a curriculum based on Dance Therapy to encourage development. Numerous studies have shown the effectiveness of Dance Therapy for a variety of conditions. By implementing concepts such as mirroring and Teaching Dance For Understanding, the Dance Therapy program will provide a productive environment for children with ASD. This program will require less resources than other types of therapies because children will not have to be supervised individually; routines are consistent and repetitive. Although more quantitative research needs to be conducted, it represents a positive step toward providing children with ASD with an optimal environment.

\section{Dance Therapy}

Dance Therapy is defined as the psychotherapeutic use of movement to promote emotional, social, cognitive and physical integration of the individual (ADTA). It is based on the notion that the mind and body are inseparable; through dance, participants can enhance both aspects. Since the establishment of the American Dance Therapy Association in 1966, there have been numerous studies conducted showing various positive outcomes with a variety of conditions (Koch et. al, 2019). Dance therapy has shown remarkable results in improved wellbeing and positive outcomes for patients with neurological disorders such as depression or dementia and physical ailments such as acute head injury or cancer (Meekums et. al, 2015; Lindner, 1982; Cohen \& Walco, 1999; Lossing, 2016). The benefits of Dance Therapy are of particular interest in children and adolescents as it has proven to be effective at providing a stabilizing environment and establishing a strong sense of self-awareness for children as young as five years old (Erfer \& Ziv, 2006). According to the National Dance Education in the Arts, dancing can help developing minds learn by connecting their cognitive intent to kinesthetic movements. Dance has been shown to assist in physical development, emotional maturity, social awareness, and cognitive development (NDEO). These developments are especially important in children with conditions such as Autism Spectrum Disorder, which carry multiple deficits. In sum, dance therapy can be an effective solution to address the complex issues faced by students with ASD.

\section{Autism Spectrum Disorder}

Autism Spectrum Disorder is a lifelong condition that has a wide variety of causes and symptoms. The most common challenges associated with children with ASD can be generalized into three categories: social interaction, speech, and nonverbal communication. Autism is a complex condition because there is a large variation in outcomes (Copeland, 
2018). The mental, physical, and social capabilities of patients lie on a wide spectrum and can range from highly functioning to severely debilitated individuals. It is one of the most common forms of developmental disabilities of childhood, rooted in atypical language and social development, in conjunction with repetitive and patterned behaviors (Scharoun et. al, 2014).

Due to these concerns, the guardians of children with ASD must bear the additional costs associated with autism. According to the US Department of Agriculture, the cost of raising a child to the age of 17 is $\$ 233,610$ (Lino, 2020). However, for children with ASD, this cost is compounded to a staggering $\$ 1.4$ to 2.4 million (Buescher et al., 2014). A significant portion of this cost is spent on a multitudinous array of therapies for the child. Ensuring optimal development of children with ASD comes with unique challenges to attend to the child's physical, cognitive, and social needs. Guardians who do not have the means to provide for this care risk delayed development and the aggravation of negative secondary symptoms such as aggression, tantrums, and self-injury within the ASD patient (Koegal et. al, 2013).

\section{Risks in children with ASD}

The characteristics of autism include physical deficits in these three categories: sensory, fine motor, and gross motor. Children with autism have extreme reactions to sensory stimulation with conditions like sensory synesthesia, in which senses are often confused for each other. There are two types of sensory synesthesia: hypersensitivity and hyposensitivity. Hypersensitive children experience an overload with even moderate levels of sensation such as light, sound, and touch. Meanwhile, hyposensitive children are not stimulated enough by normal sensory inputs, and typically seek out extra stimulation (American Addiction Center).

In addition to sensory abnormalities, $10 \sim 50 \%$ of children with ASD also show delays in motor development and show deficits in their motor functions. Fine motor skills involve detail-oriented activities like drawing, writing, or playing a musical instrument, while gross motor skills involve large-scale coordinated activities such as walking. Deficits in these skills cause autistic children to display a variety of self-stimulation behaviors like hand flapping, rocking, and eye squinting. Furthermore, they experience difficulty in walking naturally, often "toe-walking" (stepping only on the front portion of their feet), which may lead to irregular muscle development in the calves (American Addiction Center).

Children with ASD are typically characterized by sedentary lifestyles because of the limited interactions in their daily life, which leads to a significant increase in the risk of diseases such as diabetes, obesity, and heart disease (Matson et. al, 2011). Thus, physical activity is a crucial component of the healthy development of ASD patients (Macdonald et. al, 2011). Although national awareness of the condition has improved and treatments have been developed for children, physical education that exclusively focuses on children with ASD has not been explored sufficiently (Autism Society). ASD patients are also at an increased risk for other medical problems, which include, but are not limited, to insomnia, seizures, and mental health disorders. This is another reason that ASD patients need a program to keep their bodies and minds active (Copeland, 2013).

\section{Current Treatment Methods/Interventions for ASD adolescents}

ASD patients experience difficulty with controlling the muscles, which are often characterized by stereotypical movements and rigid posture. Standard treatment methods largely try to reduce these dysfunctional behaviors while encouraging cognition, language and social development (Matson et al, 2011). Treatment may also ameliorate secondary issues such as "fits of rage," abrupt mood fluctuations, hyperactivity, and aggression (Sowa, 2012). According to the $\mathrm{CDC}$, there are four main approaches to treatment for autism: the Behavior and Communication Approach, the Dietary Approach, medication, and complementary/alternative medicine. 
Among these, the behavioral approach is the most varied, and addresses the cognitive, social, and physical conditions that those with autism face. Traditionally, these methods involve one-on-one interactions with a medical professional who is surveilling the patient's actions. Types of sessions include social skills training, speech therapy, and occupational therapy (CDC, 2019). However, these therapies can cost up to $\$ 60,000$ per year, with limited coverage by insurance companies (NCSL, 2018). Even with government assistance, these expenses may be too burdensome on an average family income.

Currently, there are well-planned guidelines for general education for students with ASD. In 1984, researchers Schopler and Mesibov created the TEACCH: Treatment and Education of Autistic and Related CommunicationsHandicapped Children program. This curriculum is based on "Structured Teaching," techniques to address a host of neurological patterns, such as preference for visual information and communications problems, that are characteristic of ASD patients (Mesibov \& Shea, 2009). One of the major principles of the TEACCH program is to adapt the environment to accommodate the unique characteristics of students with autism. Much of the program involves having the children going through a routine of multiple activities, denoted clearly by visual cues (Schultheis et. al, 2000). Much of the current literature boasts of the positive outcomes of the TEACCH method (Van Bourgondien, 2013; Mesibov \& Shea, 2009). In fact, a meta-analysis by Ortega et al. (2013) notes that maladaptive behaviors decreased and social communication improved with the students with ASD. However, the authors also note that there was little to no improvement on motor, verbal, and cognitive skills. This indicates that the TEACCH curriculum must be updated or a new teaching must be developed to address these needs. Another major flaw in TEACCH methods is the lack of rigorous research standards within existing studies. Many of the studies have too small a sample size (typically 10 50 participants) to make substantive claims. The true effectiveness of TEACCH methods on a large scale are still to be determined (Cervera et al, 2018).

There is a dire need for affordable, early intervention methods for ASD patients that can stimulate their minds and bodies. While treatment methods are widely used by children with severe ASD, fewer than $25 \%$ of children with mild ASD receive any type of professional therapies that are available (Zuckerman et. al, 2017). There is a critical need for an accessible program for children with ASD to develop multiple skills. We propose that Dance Therapy can address these concerns effectively.

\section{The Benefits of Dance Therapy for Children with ASD}

Dance is a great way for children to get vigorous exercise while also teaching them coordination and movement. Dance Therapy has been proven effective for patients of a variety of neurological and physical conditions. For children with Autism, it is beneficial in that they will not only meet the exercise requirements, but also benefit from the therapeutic aspect of dance, specifically aligned with their conditions. The most prominent benefits will be the physical gains achieved through Dance Therapy. It is especially effective in increasing balance, flexibility, muscular tone and strength, endurance, and spatial awareness, which are all skills that enhance fine and gross motor deficits and sensory motor systems in children with ASD (Alpert, 2011).

Dance Therapy also provides a cognitive benefit to participants through mirroring. Mirroring, or the empathetic imitation of movement, is "a form of reflecting back but not imitating another's movements, [which] provides a powerful means to understand a child's experience, on a body level." Mirroring allows a child to see the effects of their movements on another person and, in that way, explore what his or her own body is capable of accomplishing (Pan et. al, 2009). When applied in the correct manner, this can aid in the child's cognitive development, in addition to providing them a confidence boost. We predict that the social benefits may also be substantial as students are encouraged to observe and interact with other students.

Another important feature of the Dance Therapy program will be Teaching Dance for Understanding (TDoU). This particular program helps children appreciate dance in various ways by taking advantage of the mental energy required to control and move one's body. It fosters a more enjoyable and creative approach to dance and its therapeutic qualities by providing students opportunities to "first build a movement vocabulary and a positive attitude and mindset 
towards dance (curiosity)." Students will also work towards a final performance in which they can refine their movements and feel a gratifying sentiment of accomplishment. The effectiveness of this technique lies in its ability to guide students towards actively engaging in not only dance and exercise, but also about physical literacy, concepts of movement and body, self-expression, identity, and socialization, whether it be with the other students or the instructor(s). Dance Therapy is also an effective alternative to traditional therapy when taking into consideration the social and psychological aspects of autism. Dance Therapy is a valuable opportunity for children to connect with their peers who are undergoing the same program. Furthermore, children with autism may miss important opportunities to be active and connect with their peers and the community.

\section{Solution: A Dance Program}

Our program will represent a step towards providing an accessible intervention method that will cater to the multiple needs of children with ASD. The program recognizes the significance of Structured Learning, as it accurately identifies the neurological patterns of ASD patients. Dance Therapy may have the added benefit of cognitive and physical progress in students along with improvements in social communication.

This dance program will revolve around the key concepts of both mirroring and TDoU. Mirroring will offer both social and physical benefits through empathetic imitation. Instructors will have choreographies representing various emotions; this may help students understand or express their emotions more clearly. TDoU is based on exploration, effective engagement, and skill refinement of movements, thus offering both physical and cognitive benefits. The curriculum will incorporate simple stories in which the students are the protagonist; this will instill a positive mindset and ensure confidence within the students. In addition, TDoU will increase the accuracy of the child's movements, possibly encouraging articulation of physical movements. It is important that students receive positive encouragement throughout the dance therapy sessions, regardless of their skill.

It is imperative to keep in mind that the students are children who may have difficulty moving parts of their body or cannot fully engage in detail-oriented movements. The program will therefore use easy movements to focus on broader results, such as the stretching or relaxation of the muscles, repetition, and coordination (ex. using the left arm and right leg together). There will be two versions of the same program (Easy and Standard) so that each student can follow the routine at their own pace. There should be a minimum of two teachers to teach the class, one for each version of the routine.

Since children with ASD can experience symptoms of cognitive impairment that can potentially manifest as memory difficulty, slowed thinking, and disorganization, dance routines should be constructed around a set number of moves. These moves will be repeated in different orders and frequencies throughout the song repertoire. Repetition of similar moves will encourage memorization and may help with cognitive abilities.

It is especially important to pick songs that neither overwhelm or fail to stimulate the students. In the analysis of musical preferences among cognitive styles (abilities), those with ASD preferred percussive and dynamic music styles (Greenberg et. al, 2015). Music genres will vary, but we will focus on the repetitive and easily comprehensible genre of pop music. Of particular interest is Korean Pop music, as the genre includes many upbeat songs with various rhythms that have the potential to work with different types of routines.

Finally, the final portion ( 5 to 10 minutes) should be dedicated to a brief reflection and discussion of the class with the instructor and students. This may mean asking verbal students to describe and share their emotions in a couple of words or phrases with their peers. Instructors should encourage the students who are able to communicate with their peers to socialize.

This dance program will be able to address multiple needs of children with ASD adequately with ease. Details of the program are laid out in Table I. 
Table 1. Dance Therapy principles to improve major risks in children with ASD.

\begin{tabular}{|l|l|l|}
\hline Risks in Children with ASD & \multicolumn{1}{|c|}{ Solution } & \multicolumn{1}{|c|}{ Benefits } \\
\hline $\begin{array}{l}\text { Hypersensitivity and Hyposen- } \\
\text { sitivity }\end{array}$ & $\begin{array}{l}\text { Songs will not be too fast nor too hectic. } \\
\text { Songs should be repetitive and have little } \\
\text { changes in the organization. }\end{array}$ & $\begin{array}{l}\text { Sensory stimuli will not overwhelm stu- } \\
\text { dents and keep them engaged. }\end{array}$ \\
\hline Gross Motor Skill Deficits & $\begin{array}{l}\text { - Teaching Dance for Understanding } \\
\text { - Mirroring }\end{array}$ & $\begin{array}{l}\text { Students will imitate gross motor move- } \\
\text { ments to improve their coordination. Stu- } \\
\text { dents will also learn how to dance using } \\
\text { deliberate and purposeful movements. }\end{array}$ \\
\hline Fine Motor Skill Deficits & Mirroring & $\begin{array}{l}\text { Instructors will focus on certain fine and } \\
\text { specific movements that will improve } \\
\text { their coordination. }\end{array}$ \\
\hline $\begin{array}{l}\text { Lack of Socialization and So- } \\
\text { cial Skills }\end{array}$ & $\begin{array}{l}\text { Students will share their emotions (may be } \\
\text { limited to one or a few words) at the end } \\
\text { of class. The instructors will supervise and } \\
\text { facilitate the discussions, while encourag- } \\
\text { ing the students to socialize amongst each } \\
\text { other. }\end{array}$ \\
\hline Cognitive Impairment & $\begin{array}{l}\text { Discion Time at the end of class } \\
\text { - The ability to mirror is a key cognitive } \\
\text { skill for optimal development. Students } \\
\text { will be mentally stimulated as they are } \\
\text { moving and dancing with intent. }\end{array}$ \\
\hline
\end{tabular}

\section{Limitations and Future Research}

Although there are many studies on the qualitative improvements experienced through Dance Therapy, there are not as many quantitative measures of the physical benefits of Dance Therapy. Future research needs to be done on which aspects of DMT will be most beneficial to ASD patients. One major limitation to our study was the inability to test its full capabilities due to the COVID pandemic. The pandemic poses a great risk to children with ASD as their interactions with the world are minimized and techniques within the Theory of Dance such as mirroring require the student and teacher to be physically present. There will need to also be an investigation into how to make the program effective for online sessions.

\section{Conclusion}

Although there is more recognition of the struggles and needs of children with ASD, affordable and effective treatment for groups of children is still woefully underdeveloped. Standard treatments are often expensive and inaccessible, and current dance programs for children with ASD do not adequately address the students' multiple needs. Dance Therapy offers an effective solution to these issues, as it can combine the skills for multiple activities into one. Furthermore, 
the variability of songs and dance movements allows all of the students to participate in the same activity, while being stimulated enough to be engaged in said activity. Dance Therapy will require less intensive guidance from multiple instructors, as the movements will be uniform. The realm of possibility for Dance Therapy programs is, therefore, more broad than traditional physical therapy programs.

\section{Acknowledgements}

I would like to extend my special thanks to Kathryn Marks for guiding me through the editing process. I would also like to thank Stacy Gil for advising me through the beginning stages of the project. Finally, I want to thank my family for supporting my dreams and academic pursuits. I would not have been able to get through this endeavor without them.

\section{References}

Autism and Insurance Coverage | State Laws. (2018, August 18). National Conference of State Legislatures.

Autism Spectrum Disorder (ASD). (2019, September 23). Center for Disease Control and Prevention.

https://www.cdc.gov/ncbddd/autism/treatment.html\#

Alpert, P. T. (2011). The health benefits of dance. Home Health Care Management \& Practice, 23(2), $155-157$. https://doi.org/10.1177/1084822310384689

Buescher, A.V.S., Cidav, Z, Knapp, M, Mandell, D.S. Costs of Autism Spectrum Disorders in the United Kingdom and the United States. (2014). JAMA Pediatrics, 168(8). 721-728. doi:10.1001/jamapediatrics.2014.210

Cohen, S. O., \& Walco, G. A. (1999). Dance/movement therapy for children and adolescents with cancer. Cancer Practice, 7(1), 34-42. https://doi.org/https://doi.org/10.1046/j.1523-5394.1999.07105.x

Copeland, J. N. (2018, August). What is Autism Spectrum Disorder? American Psychiatric Association. https://www.psychiatry.org/patients-families/autism/what-is-autism-spectrum-disorder

Erfer, T., \& Ziv, A. (2006). Moving toward cohesion: Group Dance/Movement Therapy with children in psychiatry. The Arts in Psychotherapy, 33(3), 238-246. https://doi.org/10.1016/j.aip.2006.01.001

Greenberg, D. M., Baron-Cohen, S., Stillwell, D. J., Kosinski, M., \& Rentfrow, P. J. (2015). Musical preferences are linked to cognitive styles. PLOS ONE, 10(7). https://doi.org/10.1371/journal.pone.0131151

History. Autism Society. https://www.autism-society.org/about-the-autism-society/history/

Koch, S. C., Riege, R. F. F., Tisborn, K., Biondo, J., Martin, L., \& Beelmann, A. (2019). Effects of dance movement therapy and dance on health-related psychological outcomes. A meta-analysis update. Frontiers in Psychology, 10. https://doi.org/10.3389/fpsyg.2019.01806

Koegel, L. K., Koegel, R. L., Ashbaugh, K., \& Bradshaw, J. (2014). The importance of early identification and intervention for children with or at risk for autism spectrum disorders. International Journal of Speech-Language Pathology, 16(1), 50-56. https://doi.org/10.3109/17549507.2013.861511 
Levenberg, M. G., Armstrong, T., \& Johnson, I. L. (2020). Teaching dance for understanding: Reconceptualizing dance in physical education. Journal of Physical Education, Recreation \& Dance, 91(6), 3-7. https://doi.org/10.1080/07303084.2020.1770519

Lindner, E. C. (1982). Dance as a therapeutic intervention for the elderly. Educational Gerontology, 8(2), $167-174$. https://doi.org/10.1080/0380127820080207

Lino, M. (2020, February 18). The Cost of Raising a Child. US Department of Agriculture.

Lossing, A., Moore, M., \& Zuhl, M. (2016). Dance as a treatment for neurological disorders. Body, Movement and Dance in Psychotherapy, 12(3), 170-184. https://doi.org/10.1080/17432979.2016.1260055

MacDonald, M., Esposito, P., \& Ulrich, D. (2011). The physical activity patterns of children with autism. BMC Research Notes, 4(1), 422. https://doi.org/10.1186/1756-0500-4-422

Matson, M. L., Matson, J. L., \& Beighley, J. S. (2011). Comorbidity of physical and motor problems in children with autism. Research in Developmental Disabilities, 32(6), 2304-2308. https://doi.org/10.1016/j.ridd.2011.07.036

Meekums, B., Karkou, V., \& Nelson, E. A. (2015). Dance movement therapy for depression. Cochrane Database of Systematic Reviews. https://doi.org/10.1002/14651858.CD009895.pub2

Mesibov, G. B., \& Shea, V. (2009). The TEACCH program in the era of evidence-based practice. Journal of Autism and Developmental Disorders, 40(5), 570-579. https://doi.org/10.1007/s10803-009-0901-6

Pan, C.-Y., Tsai, C.-L., \& Chu, C.-H. (2009). Fundamental movement skills in children diagnosed with autism spectrum disorders and attention deficit hyperactivity disorder. Journal of Autism and Developmental Disorders, 39(12), 1694-1705. https://doi.org/10.1007/s10803-009-0813-5

“Philosophy, early childhood standards.” National Dance Education Organization. https://www.ndeo.org/content.aspx?page_id=22\&club_id=893257\&module_id=55419

Sanz-Cervera, P., Fernández-Andrés, M. I., a Pastor-Cerezuela, G., \& Tárraga-Mínguez, R. (2018). The Effectiveness of TEACCH Intervention in Autism Spectrum Disorder: A Review Study. Psychologist Papers, 39(1). https://doi.org/10.23923/pap.psicol2018.2851

Scharoun, S. M., Reinders, N. J., Bryden, P. J., \& Fletcher, P. C. (2014). Dance/movement therapy as an intervention for children with autism spectrum disorders. American Journal of Dance Therapy, 36(2), $209-228$. https://doi.org/10.1007/s10465-014-9179-0

Sowa, M., \& Meulenbroek, R. (2012). Effects of physical exercise on Autism Spectrum Disorders: A meta-analysis. Research in Autism Spectrum Disorders, 6(1), 46-57. https://doi.org/10.1016/j.rasd.2011.09.001

Schultheis, S. F., Boswell, B. B., \& Decker, J. (2000). Successful physical activity programming for students with autism. Focus on Autism and Other Developmental Disabilities, 15(3), 159-162.

https://doi.org/10.1177/108835760001500306 
Van Bourgondien, M. E., \& Coonrod, E. (2013). TEACCH: An intervention approach for children and adults with autism spectrum disorders and their families. Interventions for Autism Spectrum Disorders, 75-105.

https://doi.org/10.1007/978-1-4614-5301-7_5

Virues-Ortega, J., Julio, F. M., \& Pastor-Barriuso, R. (2013). The TEACCH program for children and adults with autism: A meta-analysis of Intervention Studies. Clinical Psychology Review, 33(8), 940-953.

https://doi.org/10.1016/j.cpr.2013.07.005

What is dance/movement therapy? (2020) American Dance Therapy Association.

https://adta.memberclicks.net/what-is-dancemovement-therapy

Zuckerman, K. E., Friedman, N. D. B., Chavez, A. E., Shui, A. M., \& Kuhlthau, K. A. (2017). Parent-reported severity and health/educational services use among us children with autism: Results from a national survey. Journal of Developmental \& Behavioral Pediatrics, 38(4), 260-268. https://doi.org/10.1097/DBP.0000000000000437 